\title{
Analysis on The Performance of Weapons and Equipment Acquisition
}

\author{
Tiehong Yin *, Wenxiu Xie \\ Department of Equipment Acquisition/Equipment Academy of PLA,China \\ Unit of 96251 of PLA,China \\ *Corresponding author: Tiehong Yin,doctor,yth13264073731@163.com
}

\begin{abstract}
Performance analysis is an important part on the study of single stage and multistage collaborative performance form, mechanism, the forming rules of weapons and equipment procurement. In this paper, according to the characteristics of weapon and equipment procurement single phase operation, the inner relations between the performance influential factors are analyzed systematically and the generating mechanism of single stage performance is searched based on the views of capability and resources. Following the multistage collaborative process, such key problems as how collaborative demands generate, how to set up collaborative relationship, how to allocate the collaborative interests, how to design the incentive mechanism are clarified to search for formation mechanism of multistage collaborative performance of weapon and equipment procurement.
\end{abstract}

Key words: weapon and equipment acquisition; analysis; single stage performance; multistage collaborative performance

\section{Introduction}

In recent years, performance problems get more and more attention of people. Especially in the field of weapon and equipment procurement, performance level directly affect the defense resources input and output efficiency. To analyze the performance has important practical significance for evaluating weapon and equipment procurement performance level and improving performance management. ${ }^{1}$

\section{Single Stage Performance Generation Mechanism of Weapons and Equipment Procurement}

Performance analysis of single phase formation mechanism is the premise and foundation of weapon and equipment procurement performance evaluation of single phase. Only the deep influence factors of performance of the single phase and the role of the relationship and action process discovered, it would be possible to establish a performance evaluation framework scientifically for the single phase and back single stage performance source according to the evaluation results. $^{2}$

\subsection{Relationship between Resource and Performance}

With the advent of the era of knowledge and economy, the domestic and foreign experts and scholars and enterprise managers gradually form a consensus that enterprises' true wealth is the result of the combination of physical resources and intellectual resources. Resources is the basis of the business performance. Represented by Chen jing, zhang wei, Fan Libo, domestic scholars have found that high-tech military enterprise resources have significant positive effects on business performance on domestic empirical studies. Physical resources are the first 
asset to improve the performance. Human resources, organizational resources and the relationship resources are the second assets to revitalize the entity resource. If intellectual resources play a good role, not only can effectively promote the growth of physical resources, but also can promote enterprise performance improvement. Otherwise, it will weaken the application value of entity resources and reduce the enterprise performance. Therefore, military enterprise performance level is related to their own resources. Although countries in such aspects as policy, taxation, money give military enterprise huge support and tilt, enriching and expanding the military enterprise entity resources efficiently; If the intellectual resources of the enterprise itself can not promote synchronously and development coordinately, it will inevitably hinder the single stage performance of weapon and equipment procurement to improve. ${ }^{3}$

\subsection{Relationship between Capability and Performance}

Enterprise's ability is a kind of ability to aware and adapt market from the microscopic sense. From a macro sense it is a strategic insight and strategic reserve capacity. This ability strong or weak directly affect the level of performance. Recently, rapid development of information technology has brought the rapid change of combat style that cause new requirements on weapons and equipment. Along with time, the changes of demand will be so fast that it will put forward higher requirements on the single stage performance level of weapons and equipment procurement project. To meet the needs of the situation development, military enterprises should not only have the intrinsic ability to fast and efficiently completing a short supply of weapons and equipment, but also predict the future development trends and train strategic awareness, strategic reserves and the strategic adjustment abilities in advance from the perspective of long term strategy to meet the needs of weapons and equipment construction and development, making coordinated advance of short-term performance and long-term performance. ${ }^{4}$

\subsection{Relationships between Capability, Resource and Single Stage Performance of Weapons and equipment procurement}

As the basis of the performance generation, resources are necessary conditions to improve the single stage performance level of weapons and equipment procurement, rather than a sufficient condition. Ability is a bridge link to resources and performance, which generated in the use of resources, as well as the process of interaction with resources.Resources are basically tangible or easy to differentiate, and abilities are invisible or difficult to differentiate and hard to acquire through market means. Abilities constantly generate, accumulate and ascend in the process of task execution in each stage of weapons and equipment procurement. Based on the analysis of the generation way of short-term performance, military industrial enterprises can optimize human, organization and relationships' resources by enriching entity resources, or by enhancing the inherent ability to continuously improve the quality of weapons and equipment and service level, which would create short-term performance for weapon and equipment procurement project from the aspects of technology, time and cost, etc. Based on the analysis of the generation way of long-term performance, resources and abilities are indispensable important factors that interact, complement each other. ${ }^{5}$ 


\section{Multistage Collaborative Performance Generation Mechanism of Weapons and Equipment Procurement}

Driven by inside and outside factors, military industrial enterprises of each stage of weapons and equipment procurement voluntarily joined the synergy in pursuit of synergy benefits and gradually developed into a dynamic strategy alliance in the process of coordination. Once the development strategy of national security, weapons and equipment, weapons and equipment procurement policy, international market of military products and enterprises' core technology, inner strength, disposable resources change, new collaborative demands will generate, the original synergy order be subject to interference and impact, collaborative operation be unstable, collaborative performance level drop. ${ }^{6}$ Therefore, in order to achieve expected synergy goal and ensure that the multistage cooperative strategy of weapons and equipment procurement push in order, the corresponding cooperation power, coordination incentive coordinated mechanism of risk prevention will be needed to generate mechanism for collaborative performance.

\subsection{Elements of Synergy Performance Mechanism}

Synergy power is the premise and foundation of generating synergy performance, which is closely related with the expected earnings. In the process of coordinated operation, the necessary coordination incentive mechanism should be developed to keep military enterprises participate in the enthusiasm and initiative of synergy and ensure effective distribution of interests. ${ }^{7}$ At the same time, in order to avoid such negative synergy behaviors as opportunism, speculation harming weapons and equipment procurement performance, corresponding collaborative risk prevention mechanism is also indispensable.

\subsection{Collaborative Static Choice}

Military enterprises' collaborative static choice in different stages of the weapon and equipment procurement is looking for the intersection of their interests. Special principalagent relationship between military enterprises in the collaborative process determines that not only their own interests but cooperative partner's should also be considered to ensure balanced benefit distribution and the agent's corresponding effort to realize collaborative goal. When the information between client and agent is asymmetric, the agent's collaborative effort is difficult to know and the client's choice of cooperative static should make synergy benefits more than other opportunities expected return on the agent. ${ }^{8}$ Set $\mathrm{W}$ as the client, D as the agent, $n$ as D's collaborative effort, $s$ as random variables of other related factors, $f(s)$ as probability distribution function. For $\mathrm{A}, \mathrm{n}$ and $\mathrm{s}$ are opaque. A's synergy revenue function is $a(n, s)$. A's collaborative expense function is $\psi(a)$. W's profits are the difference between synergy income and spending. In order to maximize its own synergies, W would make reasonable expense for D's collaborative support, namely:

$$
\begin{gathered}
I=a(n, s)-\psi(a(n, s)) \\
I^{*}=\max I
\end{gathered}
$$

By getting the synergy cost provided by $\mathrm{W}, \mathrm{D}$ obtained the corresponding synergy gains $\mathrm{U}$. Set D's synergy cost as V, so it's synergy gains obtained as follows:

$$
I=U(\psi(n, s))-V(n)
$$


D’s synergy accumulation function is:

$$
I=\int I(n, \psi, s) f(s) d s
$$

If $\mathrm{D}$ do not participate in synergy, could get the opportunity benefit $I$ '. If $\mathrm{W}$ want to win D's collaborative support, should enable D gain synergy revenue of not less than the opportunity benefit, namely:

$$
\begin{gathered}
I=\int I(n, \psi, s) f(s) d s \geq I^{\prime} \\
I(n, \psi)>I\left(n^{\prime}, \psi\right)
\end{gathered}
$$

$n$ ' showed that D's collaborative behavior not reached the expected standard. Only when the above conditions have been met, D and W would make concerted efforts for collaborative goal.

It is not hard to see from the above analysis that the synergies cannot leave each other's assistance support and their cooperative statics should be both cooperative interests of partners in the collaborative process in different stages of the weapon and equipment procurement. Only in this way, the two sides will work actively in collaborative practice, achieving a win-win situation in the collaboration.

\subsection{Synergy incentive design}

To keep in order of collaborative relationships between stages of weapon and equipment procurement, the key lies in motivating partners to participate in cooperative behavior by reasonable coordination contract design ensuring that the overall and individual interests are able to achieve optimally. ${ }^{9}$ Set the weapons and equipment supply chain synergy output benefit as $S$, enterprise's collaborative efforts as $L$, its synergy cost as $H(L)$. The enterprise's synergy gains $J$ are associated with weapons and equipment supply chain synergy output benefit $S$. At the same time, the overall synergies made also cannot leave the enterprise collaborative effort.

$$
J=J(S)=J(y(L))
$$

The enterprise strive to make the synergies not less than other opportunity benefit and maximize the difference.

$$
J(y(L))-H(L)-I^{\prime} \rightarrow \max
$$

For the weapons and equipment supply chain, the goal is to make the difference between overall synergy output and the enterprise's total synergy income maximize.

$$
S-\sum_{i=1}^{3} J_{i}(S) \rightarrow \max
$$

Figure 1 show the relationship between weapon and equipment supply chain collaborative production benefits, enterprise total synergy gains (supply chain coordination costs) and the enterprises' labor paid. The maximum distance between two curves is corresponding to the optimal solution $L *$. When enterprises in different stages pay $L *$ for collaborative work, the entire supply chain's collaboration net income will be the largest. 


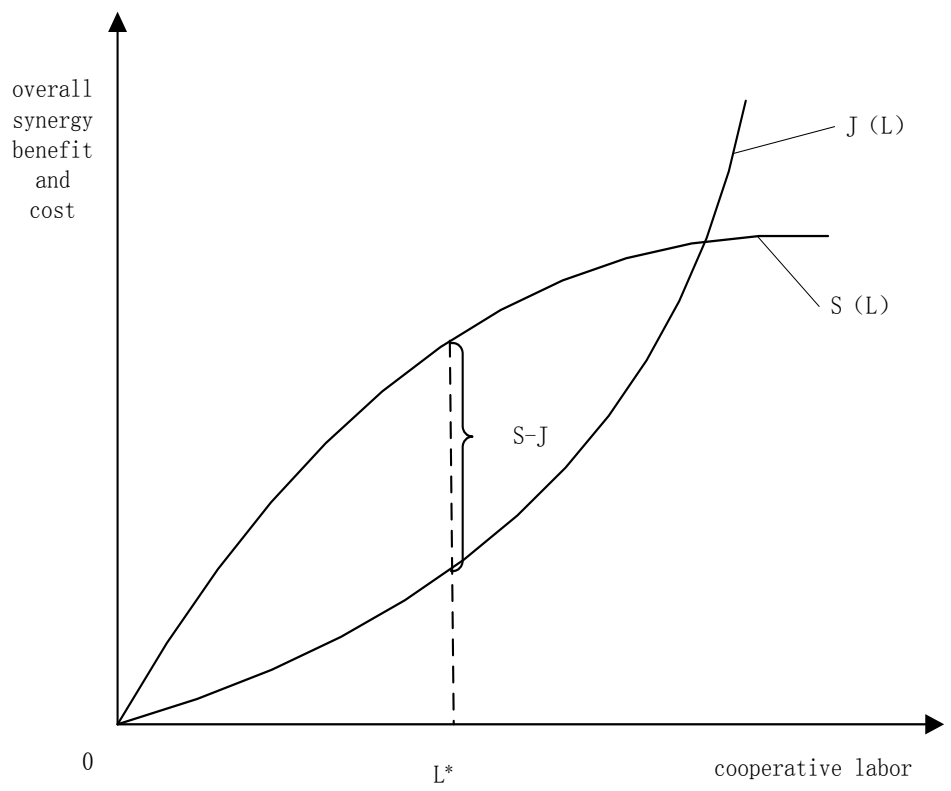

Fig. 1 - Relationships between weapons and equipment supply chain total benefits, costs and synergy labor

At the same time, the enterprise's synergy gain by paying $L *$ labor be not less than other opportunity benefits.

$$
J\left(y\left(L^{*}\right)\right)-H\left(L^{*}\right) \geq J^{\prime}\left(L^{*}\right)-H^{\prime}\left(L^{*}\right)
$$

In the client-agent contract design between military purchasing department and enterprises, corporate synergy gains can be divided into basic income and bonus income by using incentive methods for effective allocation. Synergy revenue function can be expressed as:

$$
J(y(L))=J_{0}+\theta L
$$

In above formula, $\theta$ is for coordinated contribution, $L$ is for collaborative labor, $J_{0}$ is for basic benefits. In the coordination incentive mode, the enterprises not only pursue the profit maximization, and ensure that synergies not less than other opportunity benefits.

$$
\begin{gathered}
\max [J(y(L))-H(L)]=\max \left[J_{0}+\theta L-H(L)\right] \\
J_{0}+\theta L^{*}-H\left(L^{*}\right) \geq I^{\prime} \\
J_{0}+\theta L^{*} \geq I^{\prime}+H\left(L^{*}\right)
\end{gathered}
$$

From above analysis, in the incentive collaborative interests distribution of mode, enterprises' earnings are related to collaborative labor. By improving the efficiency and quality of collaborative work, enterprises could obtain satisfactory benefits.

\subsection{Collaborative Risk Prevention}

Task execution efficiency of different stages of the weapon and equipment procurement will be of important influence to the whole supply chain coordination effect. There are many 
unpredictable factors in the operation of Weapons and equipment procurement project, which due to technical reasons or root in human reasons. The potential unstable factors are likely to produce synergistic risks. If the risks changed into accidents, the losses of weapons and equipment procurement project will be difficult to measure. ${ }^{10}$ Therefore, effective collaborative preventive means against risk are necessary to keep weapons and equipment procurement projects work properly. Benefit regulating means can be used in weapons and equipment procurement risk prevention. In the process of project operation, the client is responsible for designing collaborative risk prevention mechanism and the agent is the executor of the collaborative risk prevention. Set the agent's collaborative labor paid as $k$ that is average output value. Costs $G$ paid to the agent are associated with synergy output $r$, namely:

$$
G(r)=q+\lambda r
$$

$q$ is for the agent's fixed synergy income, $\lambda$ for collaborative risk sharing coefficient. When $\lambda$ is 0 , the agent does not assume risk loss, gaining minimum synergy income; When $\lambda$ is 1 , collaborative risk losses shall be borne by the agent alone, getting all the extra synergy income. In general, according to the principle of benefit and risk-sharing, $\lambda$ is between 0 and 1 , the optimal value obtained under the condition of considering the interests of both sides. The client's expected collaborative benefits are as follows:

$$
\begin{gathered}
E U=E(r-G(r))=E(r-q-\lambda r) \\
E U=(1-\lambda) r-q
\end{gathered}
$$

Agent synergy expectation benefit is the difference between synergy gains, collaborative labor cost and the risk cost, namely:

$$
E U=q+\lambda k-\frac{1}{2} \alpha k^{2}-\frac{1}{2} \omega \lambda^{2} \sigma^{2}
$$

In the above formula, $a$ is for collaborative labor cost coefficient, $\omega$ for collaborative risk avoidance, $\sigma^{2}$ for the normal distribution variance of synergy output benefit. The above formula's derivation is as follows:

$$
\begin{gathered}
\lambda-\alpha k=0 \\
k=\frac{\lambda}{\alpha}
\end{gathered}
$$

When these two basic conditions are meet that the client gain maximal synergy revenue and the agent's benefits not less than other opportunity return, the optimal solution of collaborative risk sharing coefficient $\lambda$ is obtained by the following objective function.

$$
\begin{gathered}
\max E(r-G(r))=(1-\lambda) k-q \\
\text { s.t. } q+\lambda k-\frac{1}{2} \alpha k^{2}-\frac{1}{2} \omega \lambda^{2} \sigma^{2} \geq U^{\prime}
\end{gathered}
$$

From the above results, the collaborative risk sharing coefficient is positively related to the agent's risk liability. At the same time, collaborative risk sharing coefficient is negatively related to the collaborative labor cost. 


\subsection{Generation model of multistage collaborative performance}

Driven by the collaborative strategy, synergy is need to promote the core competitiveness and form overall effect for weapons and equipment procurement's supply chain. Cooperative relationships are established in the process of project implementation among enterprises. Expected synergy revenues is the premise to maintain cooperative relations. For realization of the "better, faster, more province" collaborative goal, both of choosing balanced cooperative static between the overall and individual interests and designing cooperation incentive and risk prevention are need to provide basic support for collaborative operation mechanism of weapon and equipment procurement project. Therefore, collaborative performance occurs marked by quality, economy, timeliness, coordination and relationship contained in the collaborative operation mechanism. Multistage collaborative performance generation model of weapons and equipment procurement is shown in figure 2.

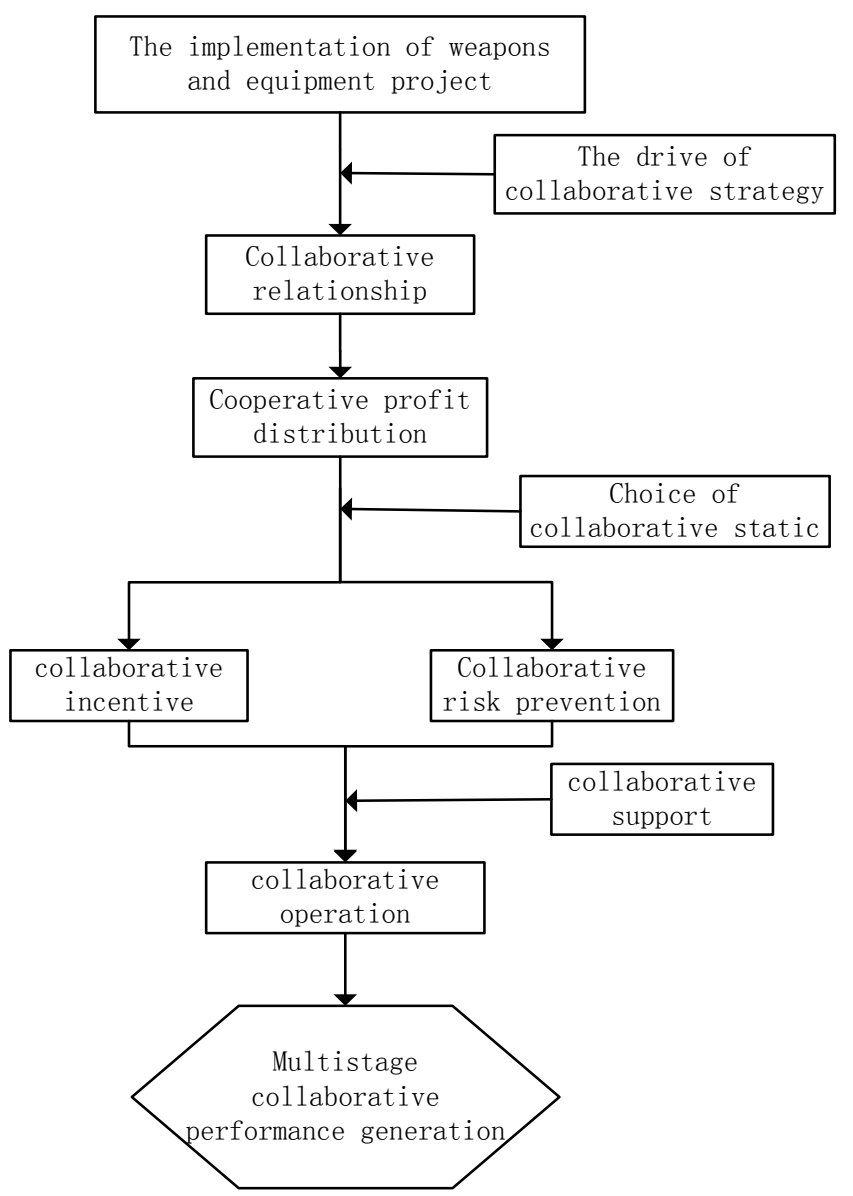

Fig. 2 - Multistage collaborative performance generation model

\section{Results and Discussion}

Ability and resource are the basic elements of single phase performance generation of weapon and equipment procurement. The interactions between ability, resources and performance generate the single stage performance. Multistage cooperative performance is a result of the combined action of the elements within the weapons and equipment procurement system. Multistage collaborative performance generation of weapons and equipment procurement 
experienced a process from disorderly to orderly, from turmoil to stability and from local to the whole. Sub-mechanisms of synergy power, coordination incentive, coordinated risk prevention and cooperative support serve for the synergy mechanism and the collaborative performance reflected in the operation.

\section{References}

1. R. Finney and D. Noel, Market pioneers, late movers, and the resource-based view: A conceptual model,J. Journal of Business Research. 2012,09:925-932.

2. M. Hall, Quantification in Manufacturing Strategy: a Methodology and Illustration,J. International Journal of Production Economics. 2014,104 (1) : 113-124.

3. J. Barney, Resource-based theories of competitive advantage: A ten-year retrospective on resource-based view,J.. Journal of Management. 2013,6:643-650.

4. M. Rafael, Technology and export behavior: A resource-based view approach,J. Internal Business Review: 2015,14:539-557.

5. J.Anderson, A Resourced-based Theory of Sustainable Rents,J. Journal of Management.2014,6: 651-660.

6. T. Davis, Effective supply chain management, J. Sloan Management Review.2009 (2) : 35-46.

7. Collaborative supply management solution from IBM. http://www.ibm.com.

8. M. Turk, Multi-company collaborative supply chain management with economical and environmental considerations,J. Computers and Chemical Engineering,2014,28:85-92.

9. D. Ross, Through Supply Chain Management: Creating Market-Winning Strategies Through Supply Chain Partnerships,M. New York: Chapman \& Hall, 2008

10. ARC Advisory Group. Collaborative manufacturing management strategies,J. ARC strategies,2012, http://www.arcweb.com 